\title{
Preliminary $k$-Values of Unbound Natural Quartzitic Gravels for Mechanistic-Empirical Pavement Design
}

\author{
Edmund Obeng1, Yaw A. Tuffour², Daniel A. Obeng², Bernard Koranteng-Yorke \\ ${ }^{1}$ Materials Division, Ghana Highway Authority, Ministry of Roads and Highways, Accra, Ghana \\ ${ }^{2}$ Department of Civil Engineering, Kwame Nkrumah University of Science and Technology, Kumasi, Ghana \\ ${ }^{3}$ Vision Consult, Accra, Ghana \\ Email: yat@engineer.com
}

How to cite this paper: Obeng, E., Tuffour, Y.A., Obeng, D.A. and Koranteng-Yorke, B. (2017) Preliminary $k$-Values of Unbound Natural Quartzitic Gravels for Mechanistic-Empirical Pavement Design. Open Journal of Civil Engineering, 7, 509-526. https://doi.org/10.4236/ojce.2017.74034

Received: August 28, 2017

Accepted: November 21, 2017

Published: November 24, 2017

Copyright () 2017 by authors and Scientific Research Publishing Inc. This work is licensed under the Creative Commons Attribution International License (CC BY 4.0).

http://creativecommons.org/licenses/by/4.0/

\begin{abstract}
The generalized constitutive model relating the resilient modulus $\left(M_{R}\right)$ of flexible pavement layer materials to stress state, adopted by the Mechanistic-Empirical Pavement Design Guide (MEPDG), contains a set of constants known as $k$-values $\left(k_{1}, k_{2}\right.$, and $\left.k_{3}\right)$ which are associated with the physical state of the layer materials. In Ghana, natural gravels constitute the predominant and sometimes the sole layer materials for most flexible pavements yet representative $k$-values of gravel materials, have not been determined to permit full application and implementation of the mechanistic-empirical design concept to pavements involving such materials. In this study, $k$-values characterising typical natural quartzitic gravels used for road construction in the country were derived by regression techniques from $M_{R}$ values determined using laboratory repeated load triaxial test. Using multiple linear regression technique, correlation relationships were then developed between the $k$-values and the physical properties of the gravels, namely, percentages of materials passing the $9.5 \mathrm{~mm}\left(\mathrm{P}_{9.5}\right)$ and $2.0 \mathrm{~mm}\left(\mathrm{P}_{2.0}\right)$ sieves, liquid limit $(\mathrm{LL})$, maximum dry density $\left(\rho_{\mathrm{dmax}}\right)$, and optimum moisture content $\left(w_{\mathrm{opt}}\right)$. The regression analysis returned $k_{1}$ values which ranged between 441 and 958 with a mean of 516; $k_{2}$ which varied between 0.0636 and 0.2168 with a mean value of 0.1216 ; and, $k_{3}$ values which ranged between 0.1257 and 3.1590 with a mean value of 1.723 . Contrary to what is mostly reported in literature, the analysis returned positive $k_{3}$ values for all but one gravel material, suggesting stress hardening under octahedral shear stress for those materials. While an expanded sample base is required to fully characterize the whole gamut of natural gravels used in pavement construction in the country, this study on limited quartzitic gravel samples has given a good indication of strong linear correlations between the
\end{abstract}


$k$-values and the index properties of the gravels, to permit estimates of the constants for such gravels be made where capability and opportunity for conducting resilient modulus tests do not exist. However, further work is recommended to fully characterise the exact nature of $k_{3}$ values for quartzitic gravels in the country.

\section{Keywords}

Flexible Pavement, Index Properties, $k$-Values, Mechanistic-Empirical Design, Quartzitic Gravel, Resilient Modulus

\section{Introduction}

In the mechanistic-empirical (M-E) design/analysis of multi-layer flexible pavement structures, the resilient response of layer materials to repeated traffic loading is quantified by the resilient modulus $\left(M_{R}\right)$ parameter. $M_{R}$ as a material stiffness parameter was initially introduced by Seed et al. [1] to measure the elastic modulus of a material at a given stress state. In pavement engineering, the parameter measures the elastic property of a layer material with consideration to the material's non-linear characteristics. $M_{R}$ values may be determined directly in the laboratory through repeated load triaxial testing and indirectly through correlation with empirical soil strength parameters (California Bearing Ratio, Soil Support Value, and Resistance Value) or by back-calculating from deflections measured with falling weight deflectometer. But because $M_{R}$ is a basic mechanistic material property, its estimation through correlations with empirical soil strength parameters is not considered appropriate as the parameters do not reflect the conditions in a pavement under repeated traffic loading [2].

In empirical pavement design approaches, representative resilient modulus values are assigned to layer materials irrespective of position in the pavement-subgrade system. This is considered a limitation since the resilient modulus of unbound soil/aggregate layers depends on stress state and is known to increase with increasing bulk stress and confining stress [3]. Layer materials, depending on their position in the pavement-subgrade system, come under different vertical stresses from the overburden and traffic loading as well as horizontal stresses from confinement.

Figure 1 shows the state of stress in a triaxial loading and the response of the loaded material under repeated loading conditions [4]. Based on the stress conditions defined in the figure, the resilient modulus is defined as;

$$
M_{R}=\frac{\sigma_{d}}{\varepsilon_{r}}
$$

where,

$M_{R}=$ resilient modulus;

$\sigma_{d}=$ repeated deviator stress $\left(\sigma_{1}-\sigma_{3}\right)$; 


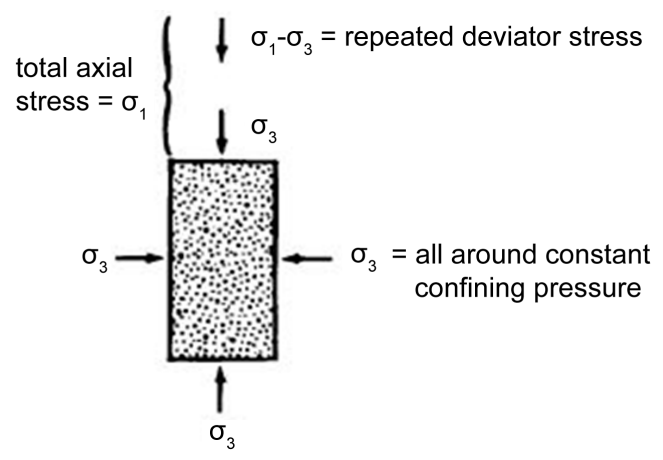

(a) Triaxial Test Stress State

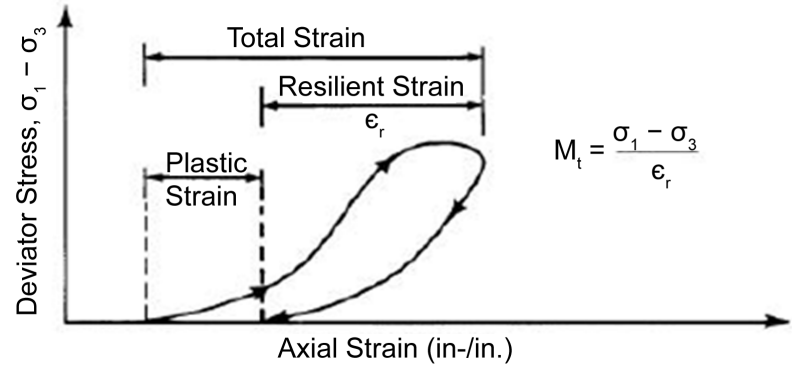

(b) Axial Specimen Response

Figure 1. Definition of $M_{R}[4]$.

$\varepsilon_{r}=$ recoverable axial strain

The basic definition of $M_{R}$ given by Equation (1) has formed the basis of several constitutive model proposals for determining resilient modulus including those of Dunlap [5], Moossazadeh and Witczak [6], Uzan [7], Witczak and Uzan [8], and the generalized model [9] given by Equation (2).

$$
M_{R}=k_{1} P_{a}\left(\frac{\theta}{P_{a}}\right)^{k_{2}}\left(\frac{\tau_{o c t}}{P_{a}}+1\right)^{k_{3}}
$$

where,

$\tau_{\text {oct }}=\frac{1}{3} \sqrt{\left(\sigma_{1}-\sigma_{2}\right)^{2}+\left(\sigma_{2}-\sigma_{3}\right)^{2}+\left(\sigma_{3}-\sigma_{1}\right)^{2}} \quad$ (octahedral stress)

$P_{\mathrm{a}}=$ atmospheric pressure

$\sigma_{1}=$ major principal stress

$\sigma_{2}=$ intermediate principal stress $\left(=\sigma_{3}\right.$ in triaxial test $)$

$\sigma_{3}=$ minor principal stress (confining pressure in triaxial test)

$\theta=$ bulk stress $\left(\sigma_{1}+\sigma_{2}+\sigma_{3}\right)$

$k_{1}, k_{2}$ and $k_{3}=$ constants ( $k$-values) related to material's physical state

The limitation inherent in empirical designs due to failure to relate $M_{R}$ to the stress state of layer materials is addressed in the Mechanistic-Empirical Pavement Design Guide (MEPDG) [9] which computes resilient modulus using Equation (2). As is clear in the model, $M_{R}$ is defined by the state of stress of the layer materials in the pavement-subgrade system and the physical state of the materials through the material constants $\left(k_{1}, k_{2}, k_{3}\right)$ known as $k$-values. For Level 1 analysis which has the highest design reliability in the Guide [9], it is recom- 
mended to determine the $k$-values from laboratory resilient modulus test conducted under repeated loading conditions to simulate traffic loading, while for Level 2 analysis, which is of intermediate reliability, $M_{R}$ may be estimated through correlations with index soil properties [10] or possibly from agency database [11].

Unlike $M_{R}$, the $k$-values are dependent only on the physical state of the material without any stress influence. The constant $k_{1}$ which can only be positive is related to material strength and tends to be higher for materials containing angular particles and less fines than those containing higher fines and rounded particles [10]; $k_{2}$ should be positive as increasing bulk stress causes stiffening effect on the material and, hence, increasing modulus while $k_{3}$ should be negative since increasing shear stress produces a softening effect on the material resulting in lower $M_{R}$ [12] [13]. A number of researchers, including [14] [15] [16], have correlated $k$-values of local soils with different soil physical properties including, but not limited to, the following: dry density, moisture content, liquid limit, plastic limit, \% clay and \% gravel. Such correlations help evaluate the $k$-values associated with the physical state of layer materials, which in turn make it possible for the resilient modulus of the layers under any stress state to be estimated using the generalized constitutive model. While literature may be replete with some such correlations for local soils, it is important to note that they are locality-specific and do not have universal application due to the variability in the geology and mineralogy of the rock masses from which soils are derived.

For fine-grained soils, the resilient modulus decreases with increase in deviator stress at a given confining stress in a behaviour known as stress-softening whereas for granular soils, the parameter increases with increase in deviator stress (stress-hardening behaviour) [3]. Other factors which affect $M_{R}$ include moisture which lowers $M_{R}$ when it is above the optimum content [17], particle shape which results in higher $M_{R}$ when it is angular to sub-angular but lower values when rounded to sub-rounded [18] [19] [20] and soil suction in the case of fine-grained subgrade soils [21].

The MEPDG approach to flexible pavement design has a lot of calibration protocols and performance predictions which require local input data for traffic, climate, subgrade and material properties [22]. For the most part, natural gravels have been the predominant layer materials used in Ghana for the construction of sub-base and base layers, particularly, of low- and medium-volume flexible pavements because the materials can generally be found within economic haul distance of most constructions and are relatively low in cost compared to crushed rock. Therefore, to properly implement and evaluate the benefits of the M-Edesign of flexible pavements involving such materials, the generalized resilient modulus model must be calibrated using data on local soils/gravels. Laboratory $M_{R}$ tests become important in the calibration process as they generate the set of data required for the determination of the $k$-values associated with the compacted layer materials/soils. This study forms part of preliminary efforts to 
establish representative $k$-values for natural gravels used in the country for flexible pavement construction.

\section{Pavement-Grade Natural Gravels in Ghana}

The Ministry of Roads and Highway's Standard Specification for Road and Bridge Works [23] uses the term "natural gravel" to include lateritic gravel, quartzitic gravel, calcareous gravel, soft stone, conglomerate, sand or clayey sand or a combination of any of the above materials. However, invariably, most natural gravels in Ghana are usually a mixture of quartz and laterite particles in a matrix of fines [24]. Gravels containing over 50\% of quartz fractions are termed quartzitic and those with over $50 \%$ laterite particles are termed lateritic. A peculiar characteristics of lateritic gravels is their reddish-brown to ochre colour, presence of concretionary particles high in iron and silica, high clay content and high plasticity [24].

In terms of suitability as flexible pavement layer materials, natural gravels are classified into grades as $\mathrm{G} 30$ (CBR $\geq 30$ ); G40 (CBR $\geq 40$ ); $\mathrm{G} 60$ (CBR $\geq 60$ ); and G80 (CBR $\geq 80$ ) using CBR, particle gradation, Grading Modulus, Atterberg Limits, Plasticity Modulus, and 10\% Fines Value. Whereas G30 and G40 grades are used for sub-base, G60 and G80 are used for base construction [23].

\section{Materials and Methods}

\subsection{Natural Gravels for Study}

Natural gravels used for road construction are mainly of two types, lateritic and quartzitic; this study focused only on the latter. The samples were collected from gravel pits distributed in five regions in the country (Figure 2). Sampling locations and sample identification are detailed in Table 1.

\subsection{Laboratory Tests}

\subsubsection{Index Property Test}

Grain size analysis was conducted on each of the gravel samples in accordance with Ghana Highway Authority (GHA) S7 Standard Method [25] whilst compaction was carried out in accordance with GHA Standard S1: Test Method for the Determination of Maximum Dry Density and Optimum Moisture Content of Soils and Soil-Aggregate Mixtures [25]. Atterberg Limits tests were carried out in accordance with ASTM D4318-10 [26] on the fines fraction (below 0.425 $\mathrm{mm}$ ) of the primary samples.

\subsubsection{Repeated Load Triaxial Test}

The $\mathrm{M}_{\mathrm{R}}$ test was conducted using the Industrial Process Controls' Universal Materials Testing Apparatus (Plate 1) equipped with a desktop computer, environmental chamber enclosing the load cell and the triaxial chamber, control and data acquisition system, air compressor, and air dryer. Gravel materials passing the $19 \mathrm{~mm}$ sieve were used for specimen preparation and compacted in a $100 \mathrm{~mm}$ 


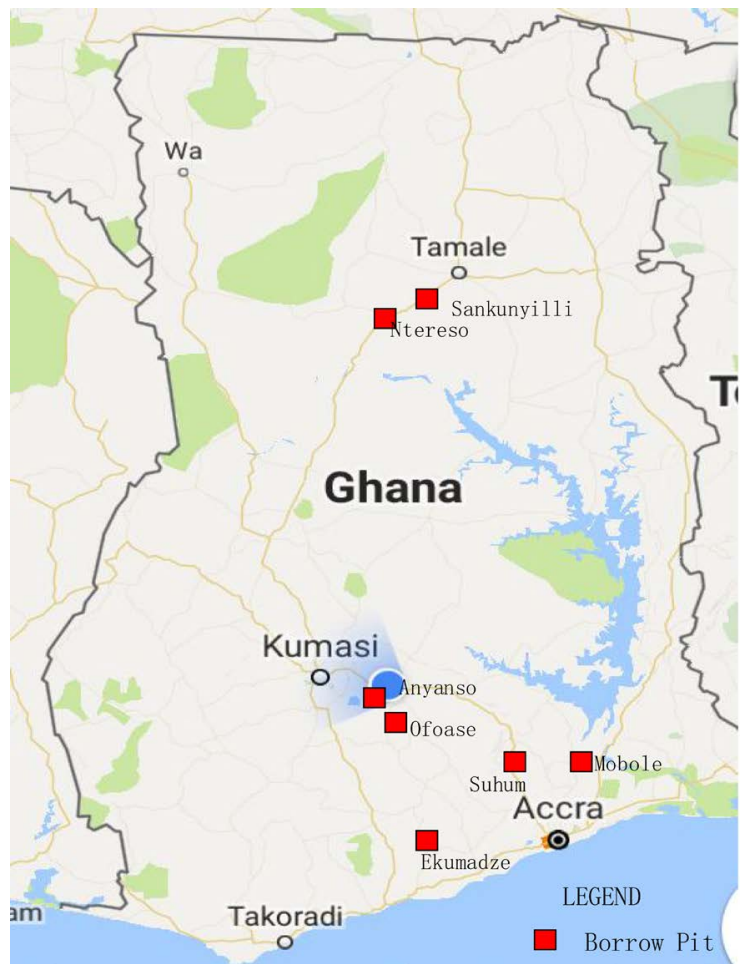

Figure 2. Map of Ghana showing locations of gravel materials used for study.

Table 1. Locations and identification of natural quartzitic gravels used for study.

\begin{tabular}{ccc}
\hline Sample Id. & Location of Depoist & Region \\
\hline NNR & Ntereso & Northern \\
SNR & Sankunyilli & Northern \\
OAR & Ofoase & Ashanti \\
AAR & Anyanso & Ashanti \\
SER & Suhum & Eastern \\
ECR & Ekumadze & Central \\
MGR & Mobole & Greater Accra \\
\hline
\end{tabular}

diameter $\times 200 \mathrm{~mm}$ high mould to the maximum dry density and optimum moisture content from the compaction characteristics of the soil. After the compaction, the specimens were removed from the mould and covered with rubber membrane for the resilient modulus test. Three specimens were prepared for each soil sample and tested for Resilient Modulus in accordance with AASHTO T307-99 test protocol [27].

\subsection{Determination of $\boldsymbol{k}$-Values of Gravel Materials}

Equation (2) which relates $M_{R}$ to the stress state and physical state of the layer material in the repeated load triaxial test was modified to the following form; 


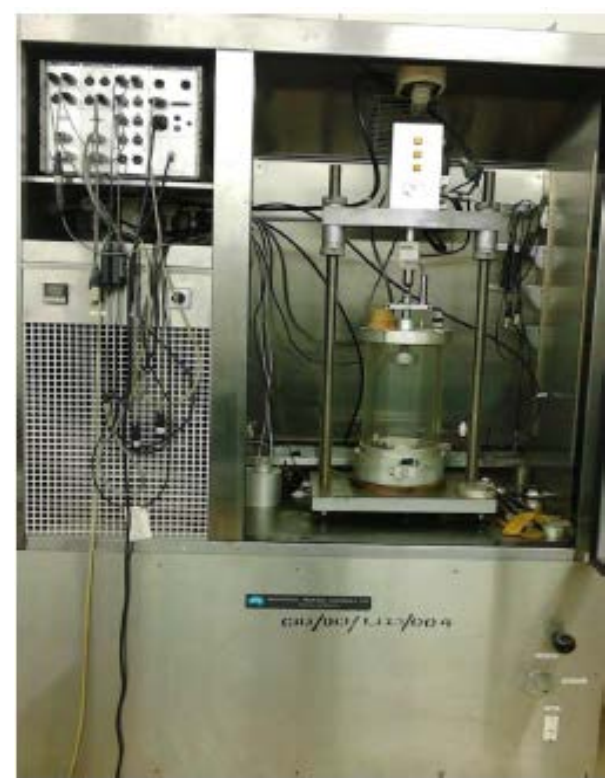

Plate 1. Resilient modulus test set-up.

$$
\log \left(\frac{M_{R}}{P_{a}}\right)=\log k_{1}+k_{2} \log \left(\frac{\theta}{P_{a}}\right)+k_{3}\left(\frac{\tau_{o c t}}{P_{a}}+1\right)
$$

Under laboratory triaxial loading conditions, $\tau_{\text {oct }}$ reduces to $\frac{\sqrt{2}}{3}\left(\sigma_{1}-\sigma_{3}\right)$.

The logarithmic-transformed $M_{R}$ values obtained from the repeated load triaxial test were regressed on the logarithmic-transformed test stresses to obtain the $k$-values in Equation (3). Correlation relationships between the $k$-values and the physical properties of the gravels were then developed using multiple linear regression technique. Based on review of literature [13] [14] [15], and for proper material and physical state representation of the compacted gravels, the index properties selected as the independent variables for the correlation relationships were the percentages of materials passing the $9.5 \mathrm{~mm}\left(\mathrm{P}_{9.5}\right)$ and $2.0 \mathrm{~mm}\left(\mathrm{P}_{2.0}\right)$ sieves, the liquid limit (LL), the maximum dry density $\left(\rho_{\mathrm{dmax}}\right)$ and the optimum moisture content $\left(w_{\text {opt }}\right)$.

\section{Results and Discussion}

\subsection{Index Properties of Gravels}

The natural gravels investigated were quartzitic in nature with colour ranging from light brown to yellowish brown. Visual inspection of the coarse fractions of the gravels from Ntereso (NNR), Suhum (SER), and Ekumadze (CER)revealed sub-angular particles with rough texture whereas fractions of the samples from Sankunyilli (SNR), Ofoase (OAR), Anyanso (AAR), and Mobole (MGR) were rounded in shape and smooth textured, suggesting some degree of transportation in the geologic past. The index geotechnical properties of the samples are summarised in Table 2. Because the fines portions of all the samples plotted 
Table 2. Index properties of natural gravels used for study.

\begin{tabular}{|c|c|c|c|c|c|c|c|}
\hline & NNR & SNR & OAR & AAR & SER & ECR & MGR \\
\hline \multicolumn{8}{|l|}{ Classification } \\
\hline AASHTO(Group Index) & A-2-4(0) & A-2-4(0) & A-2-4(0) & A-2-4(0) & A-2-4(0) & A-2-4(0) & A-2-4(0) \\
\hline Group Name & $\begin{array}{c}\text { Clayey Sandy } \\
\text { Gravel }\end{array}$ & $\begin{array}{c}\text { Clayey Sandy } \\
\text { Gravel }\end{array}$ & $\begin{array}{c}\text { Clayey Sandy } \\
\text { Gravel }\end{array}$ & $\begin{array}{c}\text { Sandy Clayey } \\
\text { Gravel }\end{array}$ & $\begin{array}{c}\text { Clayey Sandy } \\
\text { Gravel }\end{array}$ & $\begin{array}{c}\text { Clayey Sandy } \\
\text { Gravel }\end{array}$ & $\begin{array}{c}\text { Clayey Sandy } \\
\text { Gravel }\end{array}$ \\
\hline \multicolumn{8}{|l|}{ Grain Size Distribution } \\
\hline Gravel (\%) & 71 & 56 & 76 & 72 & 62 & 77 & 72 \\
\hline Sand (\%) & 18 & 26 & 14 & 13 & 22 & 15 & 22 \\
\hline Silt-Clay & 11 & 18 & 10 & 15 & 16 & 8 & 6 \\
\hline \multicolumn{8}{|l|}{ Atterberg Limits } \\
\hline Liquid Limit, LL (\%) & 28 & 22 & 28 & 25 & 29 & 28 & 18 \\
\hline Plastic Limit, PL (\%) & 19 & 15 & 19 & 16 & 19 & 19 & 11 \\
\hline Plasticity Index, PI (\%) & 9 & 7 & 9 & 9 & 10 & 9 & 7 \\
\hline \multicolumn{8}{|l|}{ Compaction Characteristics } \\
\hline Maximum Dry Density, $\rho_{\mathrm{d}}\left(\mathrm{kg} / \mathrm{m}^{3}\right)$ & 2152 & 2300 & 2216 & 2211 & 2038 & 2220 & 2305 \\
\hline Optimum Moisture Content, $\mathrm{w}_{\text {opt }}(\%)$ & 4.8 & 4.2 & 5.6 & 9.0 & 9.8 & 4.9 & 5.0 \\
\hline
\end{tabular}

above the A-Line on the Cassagrande plasticity chart, the fines were predominantly clay in content. Based on AASHTO Classification, all the samples classified as A-2-4(0) and were essentially clayey sandy gravel except that from Anyanso (AAR) which was a sandy clayey gravel. Figure 3 shows the particle size distribution curves of the gravel materials superimposed on the grading envelope for G80 and G60 base-grade gravel materials [23].

On the basis of particle gradation in terms of MRH Standards [23], almost all the gravel materials appeared to meet the requirements for G80 gravel but failed one or more other G80 requirements such as Grading Modulus, Atterberg Limits and Plasticity Modulus and hence were all clearly G60 base materials except gravel material MGR which was of G80 grade. However, according to the AASHTO T307-99 resilient modulus test protocol [27], all the materials classified as Type 1 unbound natural gravel since the proportions passing the $2 \mathrm{~mm}$ and $0.075 \mathrm{~mm}$ sieves were less than $70 \%$ and $20 \%$, respectively, with plasticity indices being less than $10 \%$.

The compaction characteristics of the gravels showed maximum dry densities ranging between $2038 \mathrm{~kg} / \mathrm{m}^{3}$ and $2305 \mathrm{~kg} / \mathrm{m}^{3}$ with an average of $2206 \mathrm{~kg} / \mathrm{m}^{3}$. Most samples had optimum water contents ranging between $4 \%$ and $6 \%$ with an average of $4.9 \%$; only two samples (AAR and SER) had optimum water contents about twice the average of those of the rest of the samples. Perhaps the higher than average silt-clay contents of the two samples could partly be the reason for the relatively high optimum water contents although sight is not lost of the fact that Sample SNR with similar percentage of silt-clay content, but substantially 


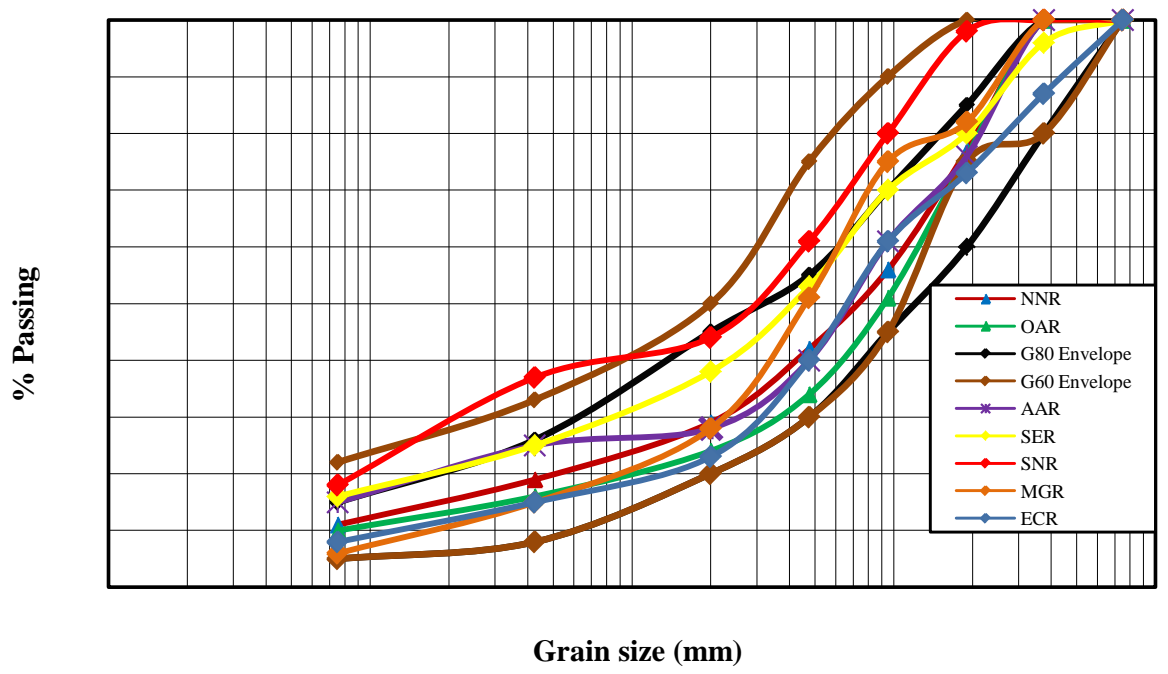

Figure 3. Particle size distribution of quartzitic gravel samples.

lower gravel fraction, belonged to the low optimum water content sample cohort.

\subsection{Resilient Modulus of Study Material}

Resilient modulus test results in the repeated load triaxial tests have been summarized in Table 3. As shown in Figure 4, the modulus increased with confining pressure because for granular soils, confinement is known to increase interlock between the individual aggregate particles within the compacted matrix, a behaviour referred to in literature as stress-hardening.

As expected, most of the granular materials exhibited increasing modulus with increasing bulk stress for a given confining stress (typified by Figures 5-7 for samples NNR, OAR, and SNR, respectively). The only exception to this stress-hardening behaviour was the gravel from Anyanso (Sample AAR) which exhibited both stress hardening and stress softening characteristics (Figure 8).

In the case of variation of $M_{R}$ with octahedral shear stress, contrary to what is touted in literature, six out of the seven gravel samples exhibited increasing modulus with increasing octahedral shear stress at a given confining stress (typified by Figure 9 and Figure 10 for samples NNR and MGR, respectively); the only exception again being Sample AAR which generally exhibited little change in modulus initially then decreasing values with further increase in shear stress (Figure 11).

\section{3. $k$-Values for Gravels}

Table 4 presents the summary of the $k$-values derived from the regression analysis of the resilient modulus values for the gravel samples. As seen in the table, $k_{1}$ values ranged between 441 and 958 with a mean of 516; $k_{2}$ varied between 0.0636 and 0.2168 with a mean value of 0.1216 while $k_{3}$, which is related to the octahedral shear stress, ranged between 0.1257 and 3.1590 with a mean value of 1.723 . 
Table 3. Summary of test results in repeated load triaxial tests on gravel materials.

\begin{tabular}{|c|c|c|c|c|c|c|c|c|c|c|c|c|c|c|c|}
\hline \multirow[b]{2}{*}{$\begin{array}{c}\text { Test } \\
\text { Sequence }\end{array}$} & \multirow{2}{*}{$\begin{array}{c}\text { Conf. } \\
\text { Pressure } \\
(\mathrm{kPa})\end{array}$} & \multicolumn{2}{|c|}{ NNR } & \multicolumn{2}{|c|}{ SNR } & \multicolumn{2}{|c|}{ OAR } & \multicolumn{2}{|c|}{ AAR } & \multicolumn{2}{|c|}{ SER } & \multicolumn{2}{|c|}{ ECR } & \multicolumn{2}{|c|}{ MGR } \\
\hline & & $\begin{array}{l}\text { Dev. } \\
\text { Stress } \\
(\mathrm{kPa})\end{array}$ & $\begin{array}{c}M_{R} \\
(\mathrm{MPa})\end{array}$ & $\begin{array}{l}\text { Dev. } \\
\text { Stress } \\
(\mathrm{kPa})\end{array}$ & $\begin{array}{c}M_{R} \\
(\mathrm{MPa})\end{array}$ & $\begin{array}{l}\text { Dev. } \\
\text { Stress } \\
(\mathrm{kPa})\end{array}$ & $\begin{array}{c}M_{R} \\
(\mathrm{MPa})\end{array}$ & $\begin{array}{l}\text { Dev. } \\
\text { Stress } \\
(\mathrm{kPa})\end{array}$ & $\begin{array}{c}M_{R} \\
(\mathrm{MPa})\end{array}$ & $\begin{array}{l}\text { Dev. } \\
\text { Stress } \\
(\mathrm{kPa})\end{array}$ & $\begin{array}{c}M_{R} \\
(\mathrm{MPa})\end{array}$ & $\begin{array}{l}\text { Dev. } \\
\text { Stress } \\
(\mathrm{kPa})\end{array}$ & $\begin{array}{c}M_{R} \\
(\mathrm{MPa})\end{array}$ & $\begin{array}{l}\text { Dev. } \\
\text { Stress } \\
(\mathrm{kPa})\end{array}$ & $\begin{array}{c}M_{R} \\
(\mathrm{MPa})\end{array}$ \\
\hline 1 & 20.7 & 10.2 & 54.3 & 10.5 & 49.6 & 11.0 & 51.8 & 9.3 & 62.3 & 9.6 & 84.4 & 9.8 & 47.1 & 8.0 & 56.8 \\
\hline 2 & 20.7 & 21.1 & 67.9 & 21.4 & 57.0 & 22.0 & 58.5 & 20.2 & 66.4 & 20.3 & 96.0 & 20.4 & 58.6 & 16.8 & 60.8 \\
\hline 3 & 20.7 & 32.3 & 78.3 & 32.5 & 66.2 & 33.4 & 67.8 & 31.1 & 66.4 & 31.1 & 106.0 & 31.0 & 71.3 & 25.9 & 71.7 \\
\hline 4 & 34.5 & 17.3 & 62.1 & 17.8 & 58.7 & 18.4 & 60.6 & 16.4 & 70.0 & 16.6 & 99.9 & 16.6 & 58.3 & 13.2 & 60.2 \\
\hline 4 & 34.5 & 35.5 & 84.1 & 36.1 & 71.3 & 36.9 & 73.8 & 34.5 & 70.2 & 34.3 & 109.7 & 34.2 & 76.2 & 28.6 & 69.7 \\
\hline 6 & 34.5 & 52.4 & 97.8 & 53.8 & 86.1 & 55.5 & 84.3 & 53.2 & 72.0 & 52.0 & 118.8 & 52.9 & 89.1 & 44.4 & 84.5 \\
\hline 7 & 68.9 & 34.6 & 81.4 & 35.7 & 76.3 & 36.8 & 77.8 & 34.6 & 78.6 & 33.4 & 112.6 & 34.5 & 77.4 & 27.8 & 70.9 \\
\hline 8 & 68.9 & 69.0 & 114.0 & 71.1 & 102.8 & 74.2 & 99.2 & 71.9 & 78.9 & 69.3 & 123.8 & 73.5 & 99.6 & 59.9 & 91.6 \\
\hline 9 & 68.9 & 101.2 & 148.1 & 107.0 & 129.1 & 111.5 & 118.7 & 111.2 & 69.2 & 105.9 & 140.2 & 110.6 & 97.8 & 93.2 & 110.9 \\
\hline 10 & 103.4 & 33.6 & 78.1 & 35.6 & 81.9 & 36.7 & 82.3 & 36.4 & 72.1 & 31.4 & 132.9 & 36.7 & 78.6 & 27.0 & 72.4 \\
\hline 11 & 103.4 & 51.0 & 101.1 & 53.8 & 95.9 & 55.4 & 93.5 & 54.8 & 73.1 & 49.1 & 138.4 & 55.0 & 83.6 & 41.8 & 82.5 \\
\hline 12 & 103.4 & 99.7 & 153.1 & 106.9 & 133.6 & 110.9 & 125.9 & 111.2 & 106.7 & 100.2 & 148.0 & 111.2 & 135.8 & 90.2 & 111.3 \\
\hline 13 & 137.9 & 48.9 & 102.6 & 53.1 & 99.6 & 55.4 & 98.7 & 54.5 & 111.8 & 44.7 & 145.6 & 55.4 & 103.2 & 40.9 & 82.9 \\
\hline 14 & 137.9 & 65.7 & 121.3 & 71.3 & 111.7 & 74.0 & 110.7 & 73.4 & 111.3 & 62.5 & 147.6 & 74.2 & 117.8 & 56.7 & 91.4 \\
\hline 15 & 137.9 & 133.2 & 177.8 & 144.3 & 155.0 & 148.0 & 139.1 & 148.2 & 83.2 & 138.0 & 153.2 & - & - & 132.0 & 114.3 \\
\hline
\end{tabular}

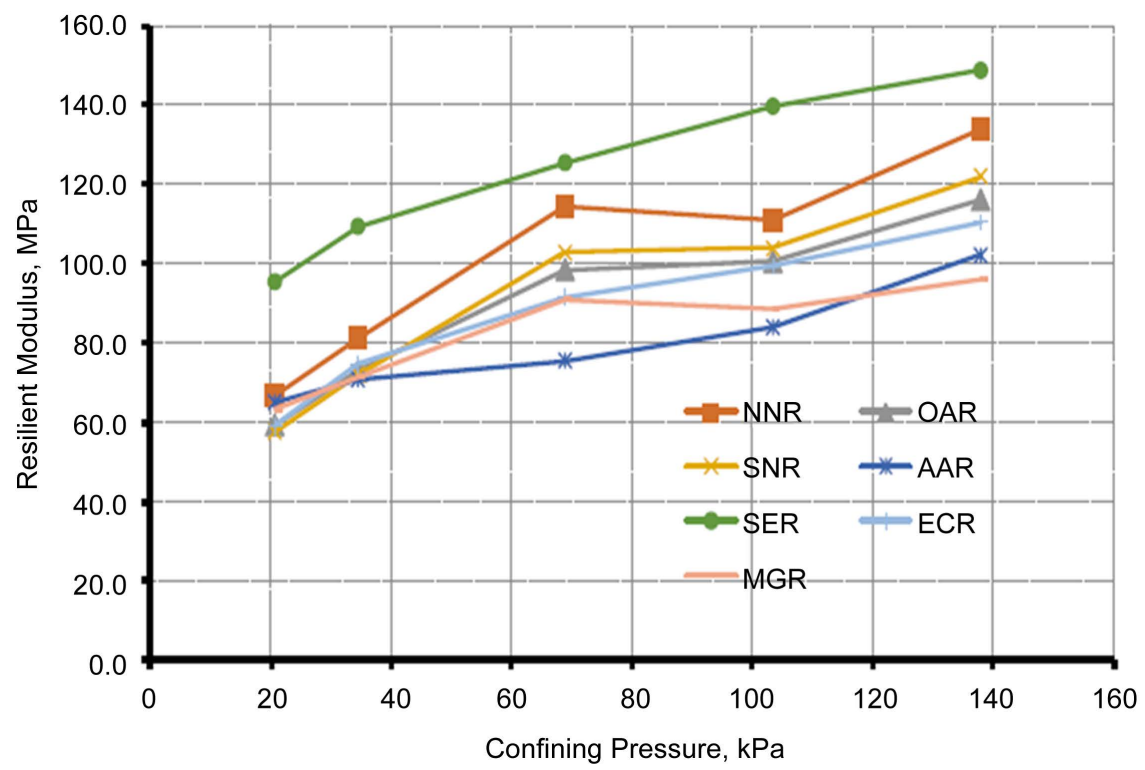

Figure 4. Laboratory $M_{R}$ for gravel samples at different confining pressures. 


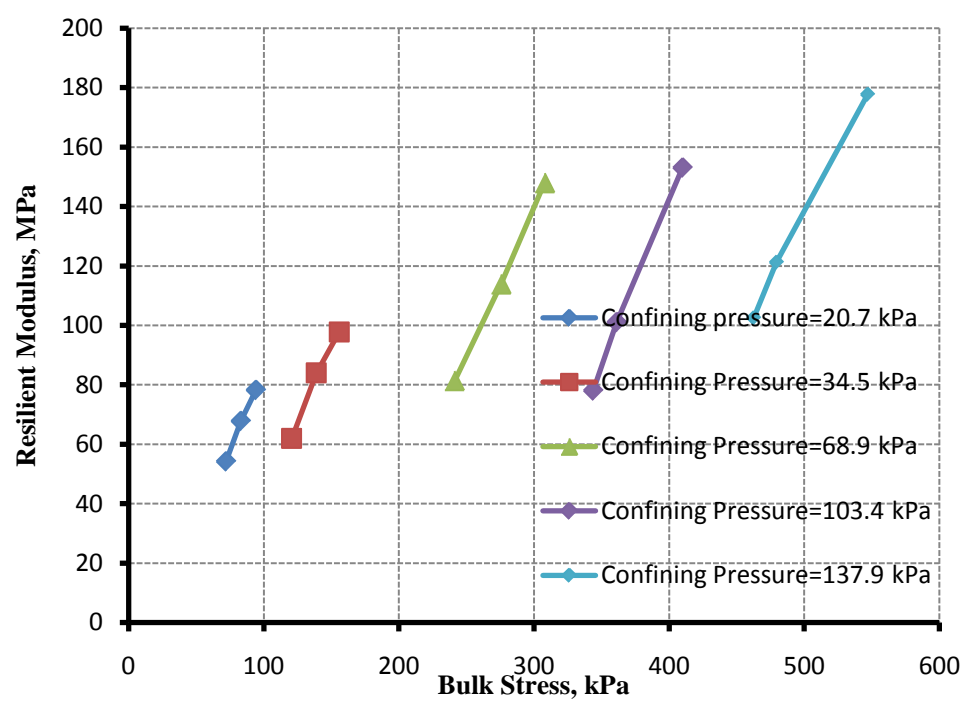

Figure 5. Laboratory $M_{R}$ for gravel sample NNR at different confining and bulk stresses.

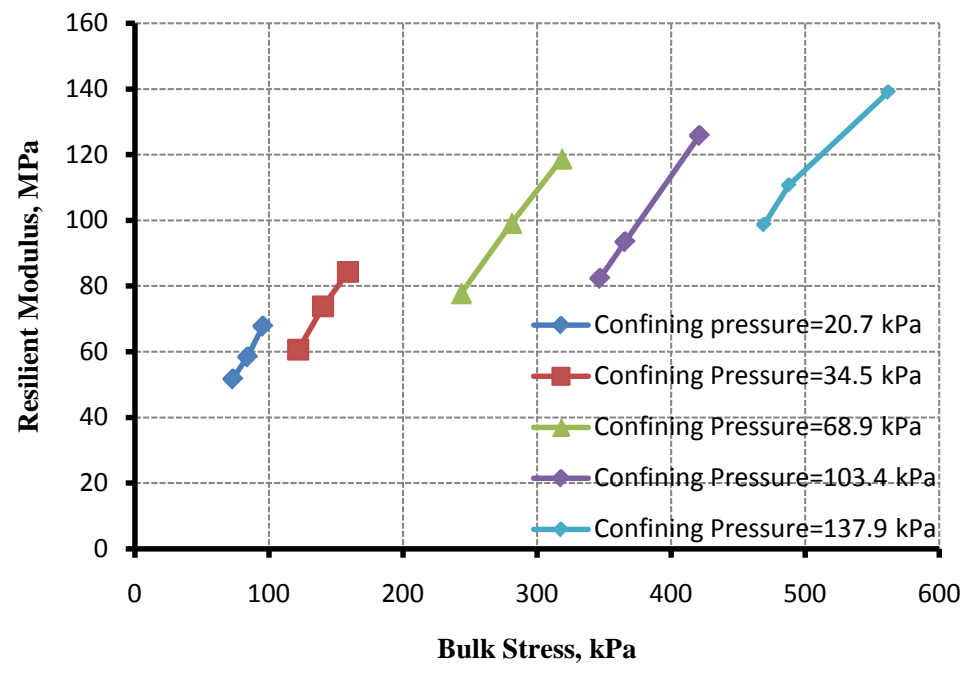

Figure 6. Laboratory $M_{R}$ for gravel sample OAR at different confining and bulk stresses.

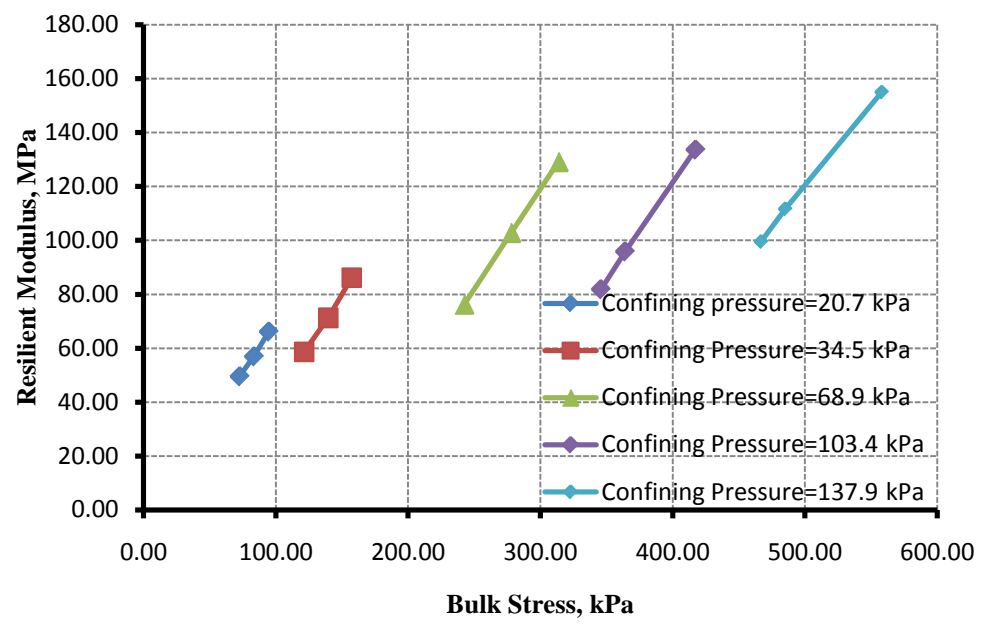

Figure 7. Laboratory $M_{R}$ for gravel sample SNR at different confining and bulk stresses. 


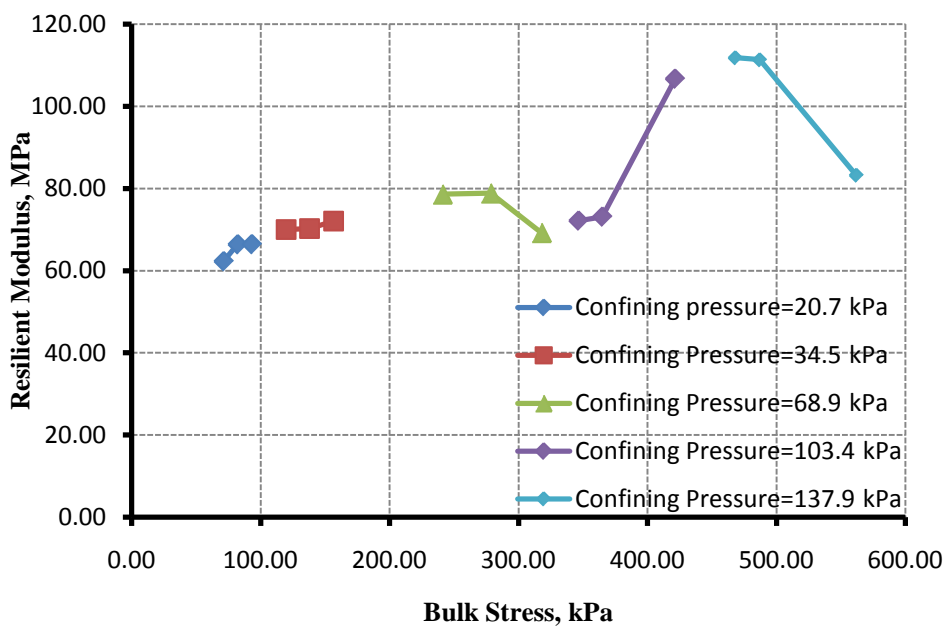

Figure 8. Laboratory $M_{R}$ for gravel sample AAR at different confining and bulk stresses.

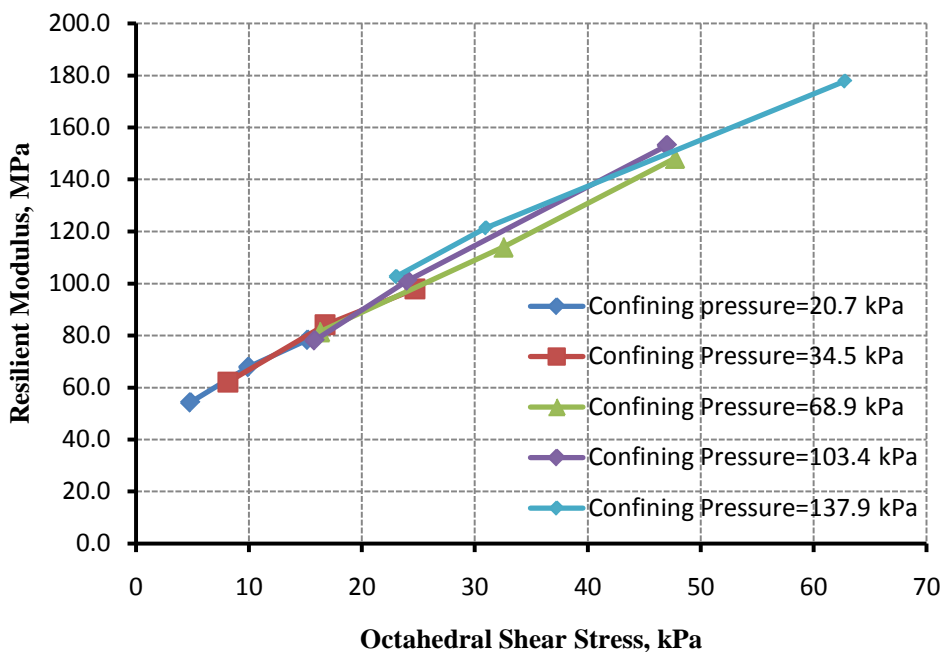

Figure 9. Laboratory $M_{R}$ for gravel sample NNR at different confining and shear stresses.

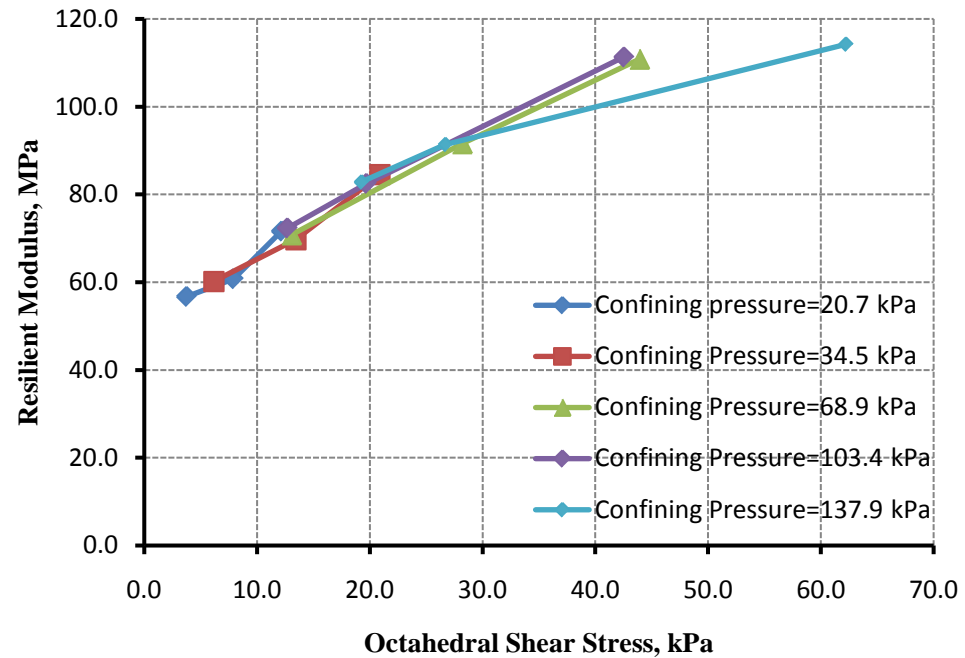

Figure 10. Laboratory $M_{R}$ for gravel sample MGR at different confining and shear stresses. 


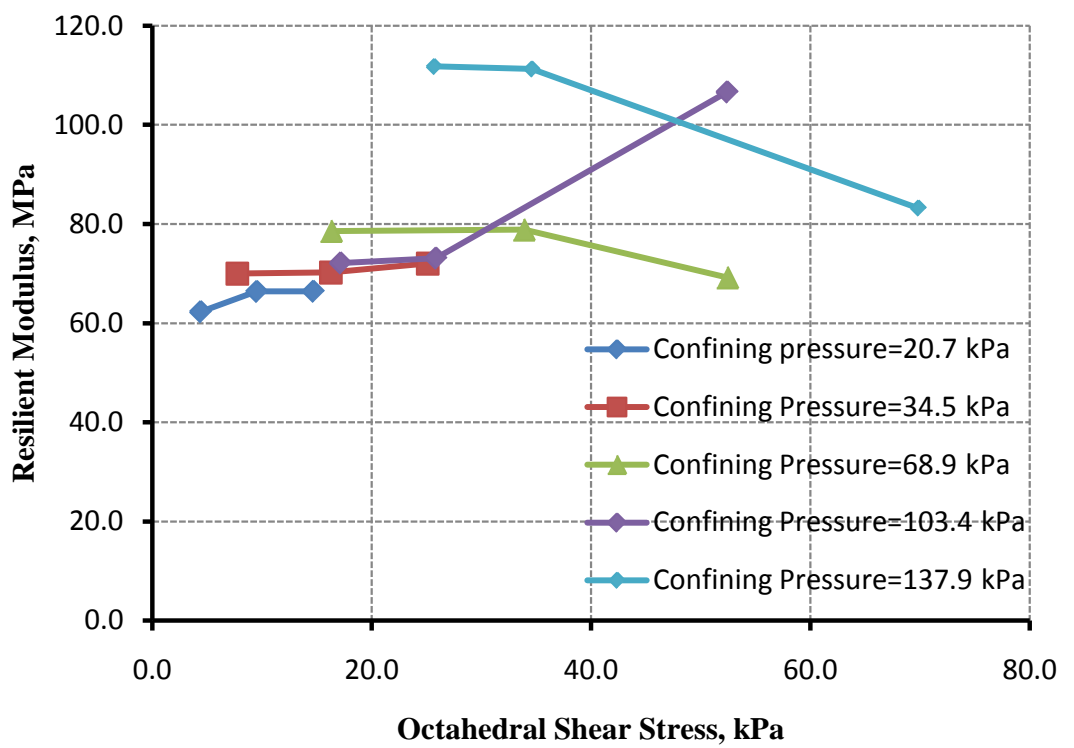

Figure 11. Laboratory $M_{R}$ for gravel sample AAR at different confining and shear stresses.

Table 4. Average $k$-values of quartzitic gravels.

\begin{tabular}{ccccc}
\hline & \multicolumn{3}{c}{ Average $k$-values } & \multirow{2}{*}{$R^{2}$} \\
\cline { 2 - 4 } Sample ID & $k_{1}$ & $k_{2}$ & $k_{3}$ & 0.99 \\
NNR & 531 & 0.0785 & 2.3883 & 0.99 \\
SNR & 503 & 0.1820 & 1.7182 & 0.98 \\
OAR & 535 & 0.1843 & 1.3425 & 0.56 \\
AAR & 676 & 0.1016 & -0.1257 & 0.94 \\
SER & 958 & 0.2168 & 0.2772 & 0.97 \\
ECR & 441 & 0.0998 & 3.1590 & 0.94 \\
MGR & 568 & 0.0636 & 1.4810 & \\
\hline
\end{tabular}

Contrary to what have been reported in literature, the regression analysis returned positive $k_{3}$ values instead of negative values for six out of the seven samples. The resilience response of a material to increase in octahedral shear stress determines the positivity or negativity of its $k_{3}$ value. As increasing shear stress is expected to lead to the softening of materials, and hence a decreasing resilient modulus, $k_{3}$ should be negative, but this phenomenon was not exhibited by the quartzitic gravels as they showed stress-hardening behaviour with increase in octahedral shear stress (see for example Figure 9 and Figure 10). The only exception to this behaviour was sample AAR from Anyanso which initially hardened at low shear stress levels but then softened at increased shear stress levels (Figure 11). It is not exactly clear what accounted for this unexpected behaviour but the coefficient of multiple determination $\left(R^{2}\right)$ associated with the regressions analysis exceeded 0.90 for the investigated materials except for the sample from 
Anyanso (AAR) for which the value was a low 0.56 (see Table 4).

The MEPDG recommends that test results and equipment should be checked for possible errors and/or test specimen disruption if $R^{2}$ for a particular test specimen is less than 0.90 [9]. Because this condition did not prevail for practically all the soils except one, it is difficult to ascribe the sample behaviour under increasing shear stress to test/equipment error. And what was even more surprising is the fact that the sample which probably could be associated with test error because of a low $R^{2}$ value was rather the gravel sample for which the analysis returned negative $k_{3}$ value in accordance with expectation based on literature. For the other samples, the higher $R^{2}$ values from the regression analysis, therefore, appeared to rule out any test errors during the triaxial test in spite of their $k_{3}$ values being positive.

Given the stress state in the repeated load triaxial test for which the intermediate principal stress $\left(\sigma_{2}\right)$ is equal to the minor principal stress or confining pressure $\left(\sigma_{3}\right)$, the generalized $\mathrm{M}_{\mathrm{R}}$ constitutive model (Equation (2)) may be re-written solely as a function of deviator stress $\left(\sigma_{d}\right)$ and confining pressure as follows:

$$
M_{R}=k_{1} P_{a}\left(\frac{\sigma_{d}+3 \sigma_{3}}{P_{a}}\right)^{k_{2}}\left(\frac{\sqrt{2} \sigma_{d}}{3 P_{a}}+1\right)^{k_{3}}
$$

It is reported that for granular materials, the resilient modulus increases with increasing confining pressure [28] and deviator stress [3] [29]. On the strength of those observations, and with reference to Equation (3), two possibilities could exist regarding the nature of the $k_{3}$ parameter: 1$)$ if $k_{3}$ were to be positive, the observations above per references [3] [28] [29] would still hold but perhaps up to some stress thresholds as stress-hardening could not be perpetuated ad infinitum with increasing deviator stress and confining pressure; 2) if $k_{3}$ were to be negative, the observation would also hold if and only if the increase in the value of $M_{R}$ due to the $k_{2}$ term (bulk stress term) more than offsets the decrease caused by the $k_{3}$ term (octahedral shear stress term). It stands to reason, therefore, that in this case, $M_{R}$ would only begin to exhibit decreasing values beyond the point where the decrease in its value caused by the $k_{3}$ term overrode the increase caused by the $k_{2}$ term. In either of the two possibilities considered above, stress-hardening behaviour of granular materials should still be anticipated only up to some threshold stress levels as confining and deviator stresses increased during the triaxial testing. This probably could be the behaviour being exhibited by Sample AAR (Figure 11). At this stage, however, no definite conclusion regarding the gravels' $k_{3}$ values can be made other than a recommendation to carry out more extensive studies and expand the gravel sample base.

\subsection{Correlation of $k$-Values with Gravel Properties}

The following correlation equations were the outcome of the regression analysis involving $k$-values from the resilient modulus test and the index physical prop- 
erties, namely, percent finer than the $9.5 \mathrm{~mm}$ and $2.0 \mathrm{~mm}$ sieves, liquid limit, maximum dry density, and optimum moisture content of the samples.

$$
\begin{aligned}
& k_{1}=2531.94-3.11 P_{9.5}+5.50 P_{2.0}-21.09 L L+0.81 \rho_{\text {dmax }}+71.30 w_{\text {opt }}, R^{2}=0.95 \\
& k_{2}=-3.54-0.005 P_{9.5}+0.008 P_{2.0}+0.014 L L+0.0014 \rho_{\text {dmax }}+0.05 w_{\text {opt }}, R^{2}=0.95(6) \\
& k_{3}=8.10+0.12 P_{9.5}-0.12 P_{2.0}+0.227 L L-0.0055 \rho_{\text {dmax }}-0.72 w_{\text {opt }}, R^{2}=0.95
\end{aligned}
$$

where,

$k_{1}, k_{2}$ and $k_{3}=k$-values of gravel

$P_{9.5}=$ percentage of gravel material passing $9.5 \mathrm{~mm}$ sieve

$P_{2.0}=$ percentage of gravel material passing $2.0 \mathrm{~mm}$ sieve

$L L=$ liquid limit

$\rho_{\mathrm{dmax}}=$ maximum dry density

$W_{\text {opt }}=$ optimum moisture content (\%)

The high $R^{2}$ values obtained for the regression suggest a strong correlation between the $k$-values and the index properties of the gravel materials. Even though the recommendation is to evaluate $k$-values from $M_{R}$ tests, the above correlations become especially useful when capability and opportunity for repeated load tests do not exist.

\section{Conclusion}

This study set out to determine the resilient modulus of quartzitic natural gravels using repeated load triaxial test and to evaluate the $k$-values $\left(k_{1}, k_{2}, k_{3}\right)$ of the materials thereof. The quartzitic gravels used in the study came from limited borrow pit sources and did not cover the whole range of natural gravel types generally used for flexible pavement construction in the country which also include lateritic gravels. The $k$-values from the resilient modulus tests were used to develop correlation equations involving the index physical properties of the gravels to help predict resilient modulus when the materials are used as pavement layer materials. The regression analysis returned $k_{1}$ values which ranged between 441 and 958 with a mean of 516, $k_{2}$ values which ranged between 0.0636 and 0.2168 with a mean of 0.1216 and $k_{3}$ values which ranged between 0.1257 and 3.1590 with a mean of 1.723 . The positive nature of the constant $k_{3}$ is in contrast to the mostly negative values reported in literature on the parameter. Nonetheless, all the $k$-values correlated highly with the following index properties of the gravels: the percentages of gravel material passing the $9.5 \mathrm{~mm}$ and $2.0 \mathrm{~mm}$ sieves, liquid limit, maximum dry density and optimum moisture content. The gravels exhibited stress hardening behaviour for the most part since the resilient moduli from the triaxial tests increased with increasing confining pressure, bulk stress, and octahedral shear stress. Even though the recommendation is to evaluate $k$-values from resilient modulus tests, the correlations developed in this study, despite the limited sample base, may permit useful estimates of the constants to be made for such gravels under any stress state and physical condition, especially 
when capability and opportunity for conducting resilient modulus tests do not exist. Further work, however, is recommended to cover the entire range of natural gravels deposits in the country and investigate into detail, the nature of the constant $k_{3}$ with increasing octahedral shear stress.

\section{Acknowledgements}

The tests in this study were carried out at the Central Laboratory, Materials Division of the Ghana Highway Authority, Ministry of Roads and Highways, Accra. The support of the Directorate of the Division and the assistance of the Technical Staff of the Laboratory are gratefully acknowledged.

\section{References}

[1] Seed, H.B., Chan, C.K. and Lee, C.E. (1962) Resilience Characteristics of Subgrade Soils and Their Relation to Fatigue Failures in Asphalt Pavements. Proceedings, First International Conference on Structural Design of Asphalt Pavements, Ann Arbor, 20-24 August 1962.

[2] George, K.P. (2004) Prediction of Resilient Modulus from Soil Index Properties. Final Report, FHWA/MS-DOT-RD-04-172, Mississippi Department of Transportation Research Division, Jackson.

[3] Kim, S., Gopalakrishnan, K. and Ceylan, H. (2012). Unbound Material Characterization with Nottingham Asphalt Tester. Construction Materials, 165, 355-365. https://doi.org/10.1680/coma.11.00007

[4] Barksdale, R.D. (1993) The Aggregate Handbook. National Stone Association, Washington DC.

[5] Dunlap, W.S. (1963) A Report on a Mathematical Model Describing the Deformation Characteristics If Granular Materials. Technical Report 1, Project 2-8-62-27, TTl, Texas A\&M University, College Station.

[6] Moossazadeh, J. and Witczak, M.W. (1981) Prediction of Subgrade Moduli for soil That Exhibits Nonlinear Behaviour. Transportation Research Record 810, TRB, National Research Council, Washington DC, 9-17.

[7] Uzan, J. (1985) Characterization of Granular Materials. Transportation Research Record 1022, TRB, National Research Council, Washington DC, 52-59.

[8] Witczak, M.W. and Uzan, J. (1988) The Universal Airport Pavement Design System, Report I of V: Granular Material Characterization. University of Maryland, College Park.

[9] National Cooperative Highway Research Program (NCHRP) (2004) Guide for Mechanistic-Empirical Design of New and Rehabilitated Pavement Structures. National Cooperative Highway Research Program 1-47A Report. Transportation Research Board, National Research Council, Washington, DC.

[10] Ji, R., Siddiki, N., Nantung, T. and Kim, D. (2014) Evaluation of Resilient Modulus of Subgrade and Base Materials in Indiana and Its Implementation in MEPDG. The Scientific World Journal, 2014, Article ID: 372838, 14. https://doi.org/10.1155/2014/372838

[11] Li, Q., Xiao, D.X., Wang, K.C.P., Hall, K.D. and Qiu, Y. (2011) Mechanistic-Empirical Pavement Design Guide (MEPDG): A Bird's-Eye View. Journal of Modern Transportation, 19, 114-133. https://doi.org/10.1007/BF03325749 
[12] Malla, R.B. and Joshi, S. (2007) Resilient Modulus Prediction Models Based on Analysis of LTPP Data for Subgrade Soils and Experimental Verification. Journal of Transportation Engineering, 133, 491-504. https://doi.org/10.1061/(ASCE)0733-947X(2007)133:9(491)

[13] Hanifa, K., Abu-Farsakh, M.Y. and Gautreau, G.P. (2015) Design Values of Resilient Modulus for Stabilized and Non-Stabilized Base. Report No. FHWA/LA.14/1521, Louisiana Transportation Research Center, Baton Rouge, Louisiana.

[14] Mohammad, L.N., Huang, B., Puppala, A. and Allen, A. (1999) Regression Model for Resilient Modulus of Subgrade Soils. Transportation Research Record 1442, TRB, National Research Council, Washington DC, 47-54. https://doi.org/10.3141/1687-06

[15] Santha, B.L. (1994) Resilient Modulus of Subgrade Soils: Comparison of Two Constitutive Equations. Transportation Research Record 1462, TRB, National Research Council, Washington DC, 79-90.

[16] Dai, S. and Zollars, J. (2002) Resilient Modulus of Minnesota Road Research Project Subgrade Soil. Transportation Research Record 1786, TRB, National Research Council, Washington DC, 20-28. https://doi.org/10.3141/1786-03

[17] Drumm, E.C., Reeves, J.S., Madgett, M.R. and Trolinger, W.D. (1997) Subgrade Resilient Modulus Correction for Saturation Effects. Journal of Geotechnical and Geoenvironmental Engineering, 123, 663-670. https://doi.org/10.1061/(ASCE)1090-0241(1997)123:7(663)

[18] Hicks, R.G. and Monismith, C.L. (1971) Factors Influencing the Resilient Properties of Granular Material. Transportation Research Record 345, TRB, National Research Council, Washington DC, 15-31.

[19] Barksdale, R.D. and Itani, S.Y. (1989) Influence of Aggregate Shape on Base Behaviour. Transportation Research Record 1227, TRB, National Research Council, Washington DC, 173-182.

[20] Thom, N.H. and Brown, S.F. (1989) The Mechanical Properties of Unbound Aggregates from Various Sources. Unbound Aggregates in Roads: Proceedings of the Fifth International Symposium on Unbound Aggregates in Roads, Nottingham, 130-142.

[21] Han, Z. and Vanapalli, S.K. (2015) Model for Predicting Resilient Modulus of Unsaturated Subgrade Soil Using Soil-Water Characteristic Curve. Canadian Geotechnical Journal, 52, 1605-1619. https://doi.org/10.1139/cgj-2014-0339

[22] Schwartz, C.W., Li, R., Ceylan, H., Kim, S. and Gopalakrishnan, K. (2013) Global Sensitivity Analysis of Mechanistic-Empirical Performance Predictions for Flexible Pavements. Transportation Research Record 2368, TRB, National Research Council, Washington DC, 12-23. https://doi.org/10.3141/2368-02

[23] MRH (2007) Standard Specification for Road and Bridge Works. Ministry of Roads and Highways, Accra.

[24] Gidigasu, D.M. (1976) Mode of Formation and Geotechnical Characteristics of Laterite Materials of Ghana in Relation to Soil Forming Factors. Building and Road Research Institute (BRRI), Kumasi.

[25] Ghana Highway Authority (GHA) (1997) Standard Methods of Test for Soils and Gravels Used in Pavement Works.

[26] ASTM D4318-10 (2010) Standard Test Methods for Liquid Limit, Plastic Limit, and Plasticity Index of Soils. 
[27] AASHTO T307-99 (2003) Standard Method of Test for Determining the Resilient Modulus of Soils and Aggregate Materials. American Association of State Highway and Transportation Officials, Washington DC.

[28] Rada, G. and Witczak, M.W. (1981) Comprehensive Evaluation of Laboratory Resilient Modulus Results for Granular Material. Transportation Research Record 810, TRB, National Research Council, Washington DC, 23-33.

[29] Maher, A., Bennert, T., Gucunski, N. and Papp, W.J. (2000) Resilient Modulus of New Jersey Subgrade Soils. FHWA Report No. 2000-01, Washington DC. 